\title{
Intention to learn influences the word frequency effect in recall but not in recognition memory
}

\author{
STEPHEN A. DEWHURST, KAREN R. BRANDT, and MELANIE S. SHARP \\ Lancaster University, Lancaster, England
}

\begin{abstract}
Watkins, LeCompte, and Kim (2000) suggested that the recall advantage for rare words in mixed lists is due to a compensatory study strategy that favors the rare words. They found the advantage was reversed when rare and common words were studied under incidental learning conditions. The present study investigated the possibility that the rare-word advantage in recognition memory is also the result of a compensatory study strategy. Experiment 1 replicated the findings of Watkins et al. that the rareword advantage in recall is eliminated under incidental learning conditions. In contrast, Experiment 2 showed that the rare-word advantage in recognition memory is maintained under both intentional and incidental learning conditions. Experiment 3 replicated the results of Experiments 1 and 2 using different stimuli and a different orienting task. Finally, Experiment 4 showed that the rare-word advantage in recognition is maintained with pure lists. These findings show that the rare-word advantage in recognition memory is not the result of a compensatory study strategy. Instead, rare words are encoded more distinctively than common words, irrespective of participants' intention to remember them.
\end{abstract}

The word frequency effect (WFE) continues to present a challenge for theoretical accounts of recall and recognition memory. Early studies suggested a frequency paradox, in which common words are more easily recalled than rare words, but rare words are more easily recognized (Anderson \& Bower, 1972; McCormack, 1972). However, the paradox was resolved by showing that the effects of frequency depend on whether rare and common words are studied in mixed or in pure lists (Gillund \& Shiffrin, 1984; Gregg, Montgomery, \& Castano, 1980). When memory is tested by free recall, studying pure lists of all common or all rare words typically leads to a recall advantage for the common words (DeLosh \& McDaniel, 1996; May \& Tryk, 1970; Shepard, 1967). Studying mixed lists containing both common and rare words either eliminates or reverses this effect (DeLosh \& McDaniel, 1996; MacLeod \& Kampe, 1996). In contrast, investigations of the WFE in recognition memory typically show an advantage for rare words, regardless of whether they are studied in mixed lists (Allen \& Garton, 1968; Duchek \& Neely, 1989; Shepard, 1967) or in pure lists (Gorman, 1961; McCormack \& Swenson, 1972). More recently, Watkins, LeCompte, and Kim (2000) showed that the direction of the WFE in recall depends also on whether words are studied under intentional or incidental learning conditions. The aim of the present study was to investigate whether the WFE in recognition memory is similarly influenced by intention to learn.

Correspondence concerning this article may be sent to S. Dewhurst, Department of Psychology, Lancaster University, Lancaster LA1 4YF, England (e-mail: s.a.dewhurst@lancaster.ac.uk).
As discussed above, recall favors common words when participants study pure lists, but this advantage is eliminated when participants study mixed lists. Watkins et al. (2000) referred to this as the mixed-list paradox. They reported a series of experiments testing the view that participants who study mixed lists adopt a compensatory strategy favoring the rare words, thereby overriding the advantage for common words observed with pure lists. According to this account, participants who study mixed lists assume that the rare words will be more difficult to remember than the common words and attempt to compensate by allocating more attention to the rare words. This proposal was previously tested and rejected by Gregg et al. (1980), who attempted to prevent the use of a compensatory strategy by asking participants (1) to attend to each word only while it was on the screen and (2) following the presentation of each word, to count backward in threes from a given number for $10 \mathrm{sec}$. If the failure to find an advantage for common words in mixed lists was the result of a compensatory study strategy favoring the rare words, precluding such a strategy should have restored the advantage. However, despite these constraints, no advantage for common words was observed. Gregg et al. concluded that the elimination of the WFE with mixed lists is not the result of a compensatory strategy favoring the rare words.

This conclusion was questioned by Watkins et al. (2000), who suggested that the participants in Gregg et al.'s (1980) study may have put more effort into remembering the rare words, despite being instructed not to do so. Watkins et al. (Experiment 2) attempted to equate the effort devoted to rare and common words by instructing participants to rate the words for pleasantness. De- 
spite this manipulation, the mixed-list paradox was not eliminated: Participants who studied pure lists recalled more common than rare words, but participants who studied mixed lists recalled equivalent numbers of rare and common words. However, Watkins et al. (Experiment 3) found an advantage for common words with both mixed and pure lists when participants rated the words for pleasantness under incidental learning conditions. Watkins et al. argued that incidental learning eliminated the compensatory study strategy by removing participants' incentive for remembering the words. This interpretation was confirmed in a further experiment in which the mixed-list paradox was completely eliminated when the critical words were presented ostensibly as distractors in a bogus memory test for other items. These findings suggest that the mixed-list paradox in recall occurs because participants adopt a compensatory study strategy that favors the rare words. When participants do not perceive the need to adopt such a strategy, the paradox is eliminated, and an advantage for common words is observed in both mixed and pure lists.

Watkins et al. (2000) briefly considered the implications of their findings for the WFE in recognition memory and concluded that this effect could not be the result of a compensatory study strategy. They noted that the WFE in recognition memory is the reverse of that observed in recall, with participants typically recognizing more rare than common words. Watkins et al. claimed that the superior recognition of rare words cannot be due to a compensatory study strategy, as the aim of such a strategy should be to favor the common words, which are less easily recognized. They argued that participants would not be aware that common words are less easily recognized than rare words, and hence would not see the need to adopt such a strategy. However, it is possible that the recognition advantage for rare words is itself the result of a compensatory study strategy. This idea is supported by the findings of Wixted (1992) and Greene and Thapar (1994) that participants in recognition experiments perceive common words as being more memorable than rare words. It is therefore possible that participants in recognition experiments adopt an encoding strategy that favors the rare words. The present study investigated this possibility.

A compensatory study explanation of the WFE in recognition memory was previously proposed by Mandler (1980), who suggested that participants devote additional rehearsal to rare words. This account was tested by Hirshman and Palij (1992) and by Kim and Glanzer (1993), who presented participants with mixed lists of common and rare words while manipulating study time. If the WFE reflects additional rehearsal of the rare words, allowing more rehearsal time at study should have increased the magnitude of the rare-word advantage. However, the two studies produced conflicting results: Hirshman and Palij found that the magnitude of the WFE remained constant, despite the variations in rehearsal time, while Kim and Glanzer found that the rare-word advantage increased with study time. This contradiction was addressed by Malmberg and Nelson (2003), who found that study time increased the WFE but only with relatively short study durations. They concluded that participants allocate additional rehearsal to rare words during the early stages of encoding but not during later stages. These findings indicate that the WFE in recognition memory is not due entirely to additional rehearsal of the rare words. One possibility is that the WFE in recognition reflects differences in the manner in which rare and common words are encoded, rather than differences in study time. Given the proposal by Watkins et al. (2000) that the rare-word advantage in recall is the result of a compensatory study strategy that is prevented by incidental learning, it is possible that incidental learning will also eliminate the rare-word advantage in recognition memory.

Previous research has shown that the WFE in recognition memory is maintained under incidental learning conditions. For example, Rao and Proctor (1984) found an advantage for rare over common words with an incidental learning condition in which the words were presented in a lexical decision task. However, investigations of word frequency effects in lexical decision have shown that rare words take longer to identify than common words (e.g., Gerhand \& Barry, 1999). It is possible that the extra time required to make the lexical decision for rare words increased their memorability relative to common words. Support for this possibility comes from the finding by Dewhurst and Hitch (1999) that items associated with longer decision times (in a category decision task) were more likely to be recognized in a subsequent memory test.

The aim of the present study was to investigate the effects of list structure and intention to learn on the WFE in recall and recognition memory. Four experiments are reported. Experiments 2, 3, and 4 investigated the effects of study strategy on the WFE in recognition memory (Experiment 3 also investigated the WFE in recall). Prior to those tests, Experiment 1 tested the robustness of the findings reported by Watkins et al. (2000). Using mixed lists, Watkins et al. found a nonsignificant advantage for rare words with intentional learning (Experiment 1) but an advantage for common words with incidental learning (Experiments 3 and 4). It was considered prudent to test the robustness of these findings before investigating the effects of intention to learn on the WFE in recognition memory.

\section{EXPERIMENT 1}

\section{Method}

Participants. Sixty-six undergraduate students from Lancaster University took part in Experiment 1. All were native English speakers. The experiment was the first in a series of experiments lasting a total of $30 \mathrm{~min}$, for which they received a payment of $£ 3$. Testing occurred in individual research cubicles.

Stimuli and Design. A set of 48 words was selected from Gilhooly and Logie (1980), consisting of 24 common words and 24 rare words. The common words had frequency counts (from Kučera 
\& Francis, 1967) of at least 100 occurrences per million, and the rare words had counts of less than 10 per million. Frequency scores were also checked in the CELEX database (Baayen, Piepenbrock, $\&$ Gulikers, 1995). The mean frequency counts per million according to CELEX were 166.75 for the common words and 3.79 for the rare words. The lists were matched for word length in letters, concreteness, frequency, and age of acquisition, according to the databases sampled by Gilhooly and Logie. The words were divided into two study lists of 24, each consisting of 12 common words and 12 rare words. Participants studied one list each. Half of the participants studied the words under intentional learning conditions, half studied them under incidental learning conditions. Within each condition, half studied List 1 and half studied List 2 . The words were presented in a different random order for each participant. The dependent measure was the number of common and rare words correctly recalled.

Procedure. Participants were allocated in equal numbers to one of three study conditions. Two of these were the study conditions used by Watkins et al. (2000); incidental learning with a rating task and intentional learning without a rating task. We added a second intentional condition in which participants rated the words for pleasantness but were notified of the subsequent recognition test. Henceforth, we will refer to the two intentional learning conditions as intentional-read and intentional-rate. Participants in the incidental learning condition were informed that they would be shown a list of words and asked to rate them for pleasantness. The words were presented one at a time on Apple Macintosh computers, and participants made their ratings by pressing one of the number keys from 1 to 7 on the top row of the keyboard $(1=$ very unpleasant, $7=$ very pleasant $)$. Each word remained on the screen until a response was made. Once the 24 words had been rated, the participants were given a surprise recall task. Before they attempted recall, the participants were asked if they had expected a memory test. None replied in the affirmative.

Participants in the intentional-rate condition rated the words for pleasantness in the manner described above but were informed prior to studying the words that they would subsequently be asked to recall them. Participants in the intentional-read condition did not rate the words for pleasantness; instead, they were simply informed that they would be shown a list of words and later asked to recall them. In this condition, each word remained on the screen for $3 \mathrm{sec}$, with an intertrial interval of $1 \mathrm{sec}$, and participants were instructed to read each word silently. Once the 24 words had been presented, participants in all three conditions were asked to count down from 10 in order to eliminate recency effects. They were then given a blank sheet of paper and asked to list all the words they could recall, in any order.

\section{Results and Discussion}

An alpha of .05 was used in all statistical analyses. Preliminary analyses showed no differences between List 1 and List 2, and therefore the data were combined into a single $3 \times 2$ mixed analysis of variance (ANOVA). The between-subjects variable was group (intentionalread vs. intentional-rate vs. incidental learning) and the within-subjects variable was frequency (common vs. rare words). Table 1 shows the mean recall proportions as a function of group and word frequency.

The main effect of group was not statistically significant $\left[F(2,63)=1.41, M S_{\mathrm{e}}=5.78, p=.25\right]$. The main effect of frequency was significant $[F(1,63)=4.00$, $\left.M S_{\mathrm{e}}=8.76\right]$, with the recall of rare words exceeding that of common words. These effects were qualified by a significant group $\times$ frequency interaction $[F(2,63)=4.43$, $\left.M S_{\mathrm{e}}=9.69\right]$. Analysis of simple main effects of frequency
Table 1

Mean Recall Proportions as a Function of Group and Word Frequency in Experiment 1

\begin{tabular}{ccc}
\hline \multicolumn{1}{c}{ Group } & Common & Rare \\
\hline Intentional-read & .39 & .53 \\
Intentional-rate & .42 & .41 \\
Incidental & .40 & .41 \\
\hline
\end{tabular}

showed that the advantage for rare words was reliably present for the intentional-read group $[F(1,63)=12.72$, $\left.M S_{\mathrm{e}}=27.84\right]$ but not for the intentional-rate or the incidental learning groups $(F<1$ in both cases). Analysis of simple main effects of group indicated that the groups did not differ in their recall of common words $(F<1)$ but differed significantly in their recall of rare words $\left[F(2,126)=4.64, M S_{\mathrm{e}}=14.61\right]$. As can be seen from Table 1, the intentional-read group recalled more rare words than either of the other groups.

The findings from Experiment 1 are not entirely consistent with those reported by Watkins et al. (2000). We found a significant rare-word advantage with intentional learning, as opposed to the null effect reported by Watkins et al. We also found that the rare-word advantage was eliminated under incidental learning conditions, whereas Watkins et al. found the effect was reversed. Nevertheless, the present findings are consistent with the view that rare words invoke a compensatory study strategy when presented in mixed lists. When participants did not perceive the need for such a strategy (under incidental learning conditions) the rare-word advantage was eliminated. The present study also showed that the rare-word advantage was eliminated under intentional learning conditions when participants rated the words for pleasantness. This result is consistent with the finding of Watkins et al. (Experiment 2). One possible explanation of this finding is that rating the words for pleasantness acts as an interference task that inhibits the use of a compensatory study strategy.

\section{EXPERIMENT 2}

Although not entirely consistent with the findings of Watkins et al. (2000), the results of Experiment 1 support their finding that the mixed-list paradox in recall can be eliminated by incidental learning. The aim of Experiment 2 was to investigate the effects of intention to learn on recognition memory. As discussed above, Watkins et al. argued that the WFE in recognition memory (an advantage for rare words over common words) could not be due to a compensatory study strategy. Participants are unlikely to be aware that recognition favors rare words, and therefore would not see the need to adopt a compensatory study strategy favoring the common words. However, it is possible that the rare-word advantage in recognition memory is itself the result of a compensatory strategy, whereby participants assume the rare words will be harder to remember and attempt to compensate 
by devoting more attention to them. If so, it should be possible to eliminate this effect under incidental learning conditions.

The WFE in recognition memory was previously attributed to the greater increase in familiarity for rare words relative to common words following their prior exposure at study (e.g., Jacoby \& Dallas, 1981; Mandler, 1980). Evidence from more recent studies, however, does not support this account. For example, using the remember-know procedure (Gardiner, 1988; Tulving, 1985), Gardiner and Java (1990) found that the advantage for rare words was observed in "remember" rather than "know" responses. These effects have been confirmed in subsequent studies (e.g., Dewhurst, Hitch, \& Barry, 1998; Kinoshita, 1995). Experiment 2 therefore used the "remember-know" procedure to conduct a finer grained analysis of the WFE in recognition memory. The design was similar to that of Experiment 1. Participants studied mixed lists of rare and common words either in one of two intentional learning conditions (one with and one without a pleasantness rating task) or under incidental learning conditions. The main changes from Experiment 1 were that participants studied longer lists of words and that their memory was tested for recognition rather than recall.

\section{Method}

Participants. Sixty-eight undergraduate students from Lancaster University took part in Experiment 2; none of them had taken part in Experiment 1. Twenty took part in the intentional-read condition, 24 in the intentional-rate condition, and 24 in the incidental learning condition.

Stimuli and Design. A set of 80 words ( 40 common and 40 rare) were selected from Gilhooly and Logie (1980). The common words had frequency counts (from Kučera \& Francis, 1967) of at least 100 occurrences per million, and the rare words had counts of less than 10 per million. The mean frequency counts per million from CELEX (Baayen et al., 1995) were 129.83 for the common words and 3.85 for the rare words. The words were divided into two lists of 40, with each list consisting of 20 common and 20 rare words. The lists were matched for word length in letters, concreteness, imageability, and age of acquisition. One of the lists was presented to participants at encoding and later provided the target items in the recognition test; the other set provided the distractor items for the recognition test. Half of the participants in each condition studied List 1, the other half studied List 2. Study items within each set were presented in a different random order for each participant. The dependent measures were the numbers of "remember" $(R)$ and "know" $(K)$ responses produced in the recognition test.

Procedure. Study items were presented one at a time on Apple Macintosh computers. Participants in the incidental learning group were told they were taking part in a rating experiment in which their task was to rate a set of words and faces. They were told the experiment was investigating interrater reliability in the ratings of various types of stimuli. Participants were informed that they had been randomly allocated to the group who rated the words first, followed by the faces (in fact all participants rated the words first). Participants then saw one of the mixed lists of rare and common words used in the intentional learning condition. The words were presented one at a time, and participants rated the pleasantness of each item by pressing a response key, from 1 (very unpleasant) to 7 (very pleasant). The words remained on the screen until a response key was pressed. Participants were then given a booklet containing a set of unfamiliar female faces and were asked to rate the typicality of each face using a 9-cm rating scale. This task was used to collect normative data for an unrelated series of experiments. For the purposes of the present study, it provided a plausible cover story and ensured a filled retention interval of sufficient duration for the patterns of $R$ and $K$ responses to stabilize. The face rating task took approximately $10 \mathrm{~min}$, after which time the participants were given a surprise recognition test for the words. Before commencing the recognition task, participants were asked if they had expected a memory test for the words. None replied in the affirmative.

The procedure for participants in the intentional-rate group was identical to the above, with the addition that they were informed prior to the pleasantness rating task that they would later be given an unspecified memory test for the words. Participants in the intentionalread group were simply instructed to read each word silently as it appeared on the screen in preparation for an unspecified memory test. For these participants, each word remained on the screen for $3 \mathrm{sec}$, with an intertrial interval of $1 \mathrm{sec}$. The recognition test was the same for all three groups and consisted of the 40 target items plus the 40 distractor items, presented on both sides of a single sheet of paper, with each side containing two columns of 20 words each. The letters $R, K$, and $G$ appeared to the right of each word. Participants were given the following instructions:

These pages contain a set of words, some of which appeared in the list you saw earlier. The letters "R," "K," and "G" are printed to the right of each item. Your task is to identify those items that appeared in the earlier phase of the experiment. If you believe an item did not appear in the earlier phase, leave it and go on to the next item. If you believe an item did appear in the earlier task then underline it. In addition, each time you underline an item please circle either $R, K$, or $G$. These stand for "remember," "know," and "guess," and refer to the nature of your conscious experience as you recognize the item. A "remember" response is one in which you can consciously recollect the appearance of that item in the first part of the experiment. You may recall details of the event, such as any thoughts, feelings, or memories you experienced when you saw the item, an association you formed with another item, or some aspect of the item's physical appearance. A "know" response is one in which you recognize the item because it feels familiar from the first part of the experiment, but you cannot recall any details of its occurrence. You recognize the item purely on the basis of familiarity. There may be other items that you neither recollect nor recognize on the basis of familiarity, but which you cannot definitely reject. You have the option of making a "guess" response to these items if you wish. Please think carefully about each item, and make a "remember," "know," or "guess" decision for each item that you recognize.

The recognition test was participant paced and took approximately 5 min to complete.

\section{Results and Discussion}

Table 2 shows the mean proportions of correct and false-positive $R$ and $K$ responses to common and rare words, plus overall hits, false alarms, and discrimination $\left(A^{\prime}\right)$, for the intentional and incidental learning groups. The data were entered into a 3 (group) $\times 2$ (frequency) $\times$ 2 (response type) ANOVA. Response type was treated as an independent variable in order to allow us to compare the effects of intention to learn and frequency on $R$ and $K$ responses. Guess responses were not included in the analysis. The main effect of group was not significant $\left[F(2,65)=1.81, M S_{\mathrm{e}}=14.85, p=.17\right]$. The main effect of frequency was significant $\left[F(1,65)=38.64, M S_{\mathrm{e}}=\right.$ 42.45], with the recognition of rare words exceeding that of common words. Finally, the main effect of response type was significant $\left[F(1,65)=204.29, M S_{\mathrm{e}}=7,903.60\right]$, with participants overall making more $R$ than $K$ responses. Crucially, group did not interact significantly with frequency $(F<1)$, indicating that intention to learn did not 
Table 2

Mean proportions of Hits and False Alarms as a Function of Group, Word Frequency, and Response Type, Plus $\boldsymbol{A}^{\prime}$, for Experiment 2

\begin{tabular}{|c|c|c|c|c|c|c|}
\hline \multirow{2}{*}{$\begin{array}{c}\text { Response } \\
\text { Type }\end{array}$} & \multicolumn{2}{|c|}{ Hits } & \multicolumn{2}{|c|}{ False Alarms } & \multicolumn{2}{|l|}{$A^{\prime}$} \\
\hline & Common & Rare & Common & Rare & Common & Rare \\
\hline \multicolumn{7}{|c|}{ Intentional-Read } \\
\hline Remember & .57 & .65 & .05 & .03 & & \\
\hline Know & .17 & .15 & .10 & .07 & & \\
\hline Overall & .74 & .80 & .15 & .09 & .85 & .90 \\
\hline \multicolumn{7}{|c|}{ Intentional-Rate } \\
\hline Remember & .73 & .83 & .03 & .01 & & \\
\hline Know & .07 & .06 & .07 & .04 & & \\
\hline Overall & .81 & .89 & .09 & .05 & .90 & .95 \\
\hline \multicolumn{7}{|c|}{ Incidental } \\
\hline Remember & .57 & .71 & .03 & .01 & & \\
\hline Know & .20 & .15 & .08 & .05 & & \\
\hline Overall & .78 & .86 & .10 & .05 & .89 & .94 \\
\hline
\end{tabular}

reliably influence the WFE. The interaction between group and response type was significant $[F(2,65)=$ 5.27, $\left.M S_{\mathrm{e}}=204.06\right]$. As can be seen in Table 2, the intentional-rate group made more $R$ responses and fewer $K$ responses than either of the other groups. The interaction between frequency and response type was also significant $\left[F(2,65)=5.27, M S_{\mathrm{e}}=14.85\right]$. Overall, participants made more $R$ responses to rare than to common words $\left[F(1,130)=56.79, M S_{\mathrm{e}}=161.06\right]$ and more $K$ responses to common than to rare words $[F(1,130)=3.94$, $\left.M S_{\mathrm{e}}=1.18\right]$. The three-way interaction was not significant $(F<1.3)$.

False alarms were also entered into a 3 (group) $\times 2$ (frequency) $\times 2$ (response type) ANOVA. The main effect of group was not significant $\left[F(2,65)=1.98, M S_{\mathrm{e}}=\right.$ $7.84, p=.15]$. The main effect of frequency was significant, with participants falsely recognizing more common than rare words $\left[F(1,65)=21.68, M S_{\mathrm{e}}=16.69\right]$. The main effect of response type was also significant, with participants making more false $K$ than $R$ responses $\left[F(1,65)=16.73, M S_{\mathrm{e}}=47.19\right]$. None of the interactions were significant $(F<1$ in all cases).

Analysis of $A^{\prime}$ data showed a significant main effect of group $\left[F(1,65)=4.39, M S_{\mathrm{e}}=0.03\right]$, with the intentionalrate group showing the highest discrimination and the incidental group the lowest. The main effect of frequency was also significant $\left[F(1,65)=50.28, M S_{\mathrm{e}}=0.07\right]$, with rare words showing greater levels of discriminability relative to common words. The interaction between group and frequency was not significant $(F<1)$.

The results of Experiment 2 support previous findings of a recognition advantage for rare words relative to common words (e.g., Duchek \& Neely, 1989; Gregg, 1976; Shepard, 1967). The presence of the WFE in $R$ responses is consistent with previous findings by Dewhurst et al. (1998), Gardiner and Java (1990), and Kinoshita (1995). As $R$ responses have been found to reflect the distinctiveness of to-be-remembered items (Dewhurst et al., 1998; Rajaram, 1996), the presence of the WFE in $R$ re- sponses suggests rare words are encoded more distinctively than common words. The results of Experiment 2 also show that the recognition advantage for rare words in mixed lists is obtained under both intentional and incidental learning conditions and both with and without a pleasantness rating task at encoding. The results from all three groups show the same overall pattern, with rare words giving rise to reliably more $R$ responses than common words. This situation contrasts with the findings of Watkins et al. (2000) and Experiment 1 of the present study that the rare-word advantage in the recall of mixed lists is eliminated under incidental learning conditions or when participants are asked to rate the words for pleasantness. The present findings suggest the recognition advantage for rare words is not the result of a compensatory study strategy. They also replicate previous findings of a word frequency mirror effect, in which rare words show both a higher hit rate and a lower false alarm rate than common words (e.g., Glanzer \& Adams, 1985, 1990).

\section{EXPERIMENT 3}

The findings of Experiment 1 supported the view of Watkins et al. (2000) that the mixed-list advantage for rare words in recall is the result of a compensatory study strategy. However, the rare-word advantage was eliminated under both incidental and intentional learning conditions when participants were instructed to rate the words for pleasantness. It is therefore impossible to determine whether the elimination of the rare-word advantage was due to incidental learning per se or to the rating task. The aim of Experiment 3 was to investigate whether the rare-word advantage is eliminated by incidental learning when participants are not required to rate the words for pleasantness. Participants were therefore asked simply to read the words aloud in both the incidental and intentional learning conditions. Experiment 3 also allowed us to address a discrepancy between the findings of Watkins et al. that incidental learning reversed the rare-word advantage, and Experiment 1, that incidental learning merely eliminated it.

Half of the participants in Experiment 3 were tested for recall and half for recognition. Within each group, half studied the words under intentional and half under incidental learning conditions. The cover story for the incidental learning conditions was that the purpose of the experiment was to measure pronunciation patterns. Experiment 3 also used a new set of stimuli, taken from Gilhooly and Logie (1980), that varied in frequency but were matched for length in letters, concreteness, imageability, and age of acquisition.

\section{Method}

The methods for the recall and recognition groups followed those used in Experiments 1 and 2, respectively, with the following modifications: A new group of 40 participants were allocated to the recall condition (20 in the incidental and 20 in the intentional learning group). Participants in these groups saw 24 words (12 rare and 
Table 3

Mean Recall Proportions as a Function of Group and Word Frequency in Experiment 3

\begin{tabular}{ccc}
\hline Group & Common & Rare \\
\hline Intentional & .31 & .43 \\
Incidental & .26 & .30 \\
\hline
\end{tabular}

12 common) presented one at a time for $3 \mathrm{sec}$ each and with an interval of $1 \mathrm{sec}$. Participants in the incidental learning group were told the purpose of the experiment was to measure pronunciation patterns; to this end, they were instructed to speak each word aloud into a microphone. This instruction was merely a cover story, and the computer was not set to accept a vocal response. Participants in the intentional group were also instructed to speak each word aloud into a microphone but were informed that they would be asked to recall the words afterward.

A second group of 40 participants were allocated to the recognition conditions ( 20 to the incidental group and 20 to the intentional group). Each participant studied 40 words (20 rare and 20 common). As in the recall groups, participants were instructed to speak the words aloud into a microphone and received instructions appropriate to either the incidental or the intentional learning condition. The recognition test included 80 words, with targets and lures counterbalanced across participants, and was administered in the same manner as in Experiment 2.

\section{Results and Discussion}

The recall data were entered into a $2 \times 2$ mixed ANOVA in which the between-subjects variable was group (intentional vs. incidental learning) and the within-subjects variable was frequency (rare vs. common words). A significant main effect of group was observed, whereby participants in the intentional learning group recalled more words overall than did participants in the incidental learning group $\left[F(1,38)=6.79, M S_{\mathrm{e}}=\right.$ 24.20]. A significant main effect of frequency was also observed, whereby rare words were better recalled overall than common words $\left[F(1,38)=15.97, M S_{\mathrm{e}}=18.05\right]$. These effects were qualified by a significant group $X$ frequency interaction $\left[F(1,38)=4.24, M S_{\mathrm{e}}=5.00\right]$. Analysis of simple main effects showed that the rareword advantage was reliably present in the intentional learning group $\left[F(1,38)=18.60, M S_{\mathrm{e}}=21.03\right]$ but not in the incidental learning group $\left[F(1,38)=1.79, M S_{\mathrm{e}}=\right.$ $2.03, p=.19]$. The mean recall proportions as a function of group and frequency are displayed in Table 3.

The recognition data were entered into a 2 (group) $\times 2$ (frequency) $\times 2$ (response type) ANOVA. Table 4 shows mean proportions of correct and false-positive $R$ and $K$ responses as a function of group and frequency, plus overall hits, false alarms, and $A^{\prime}$. The main effect of group was not significant $\left[F(1,38)=1.93, M S_{\mathrm{e}}=22.50, p=\right.$ .17]. A significant main effect of Frequency was observed, whereby participants recognized more rare than common words overall $\left[F(1,38)=41.44, M S_{\mathrm{e}}=105.63\right]$. The main effect of response type was also significant, with participants making more $R$ than $K$ responses overall $\left[F(1,38)=38.09, M S_{\mathrm{e}}=1,199.03\right]$. The only significant interaction was between frequency and response type $\left[F(1,38)=126.08, M S_{\mathrm{e}}=476.10\right]$. Analysis of sim- ple main effects showed that more $R$ responses were made to rare than to common words $\left[F(1,76)=162.88, M S_{\mathrm{e}}=\right.$ 515.11], whereas more $K$ responses were made to common than to rare words $\left[F(1,76)=21.06, M S_{\mathrm{e}}=66.61\right]$.

A similar analysis of false alarms showed a significant main effect of response type, whereby false alarms were more likely to be categorized as $K$ than as $R$ responses $\left[F(1,38)=18.09, M S_{\mathrm{e}}=28.06\right]$. The main effects of group and frequency were not significant $(F<1.2$ in both cases). The only significant interaction was between group and frequency $\left[F(1,38)=9.09, M S_{\mathrm{e}}=3.91\right]$. Analysis of simple main effects showed that participants in the intentional learning group falsely recognized more common than rare words $\left[F(1,38)=8.40, M S_{\mathrm{e}}=3.61\right]$, whereas participants in the incidental learning group showed a nonsignificant trend in the opposite direction $\left[F(1,38)=1.86, M S_{\mathrm{e}}=0.80, p=.18\right]$. Analysis of $A^{\prime}$ showed a significant main effect of group $[F(1,38)=$ $\left.17.10, M S_{\mathrm{e}}=0.06\right]$, with the incidental group showing higher discrimination scores than the intentional group. Table 4 shows an effect of frequency in the intentional but not in the incidental group. However, neither the main effect of frequency not the interaction was reliable ( $F=2.70$ and 3.40 , respectively).

The main finding from Experiment 3 was that incidental learning eliminated the mixed-list advantage for rare words in recall but not in recognition memory. Moreover, these effects were observed after removing the confound between intention to learn and orienting task that was present in Experiments 1 and 2, suggesting that the elimination of the rare-word advantage in recall was due to incidental learning and not simply to the pleasantness rating task. The elimination of the rare-word advantage in recall was consistent with the view of Watkins et al. (2000) that the effect is due to a compensatory study strategy that favors the rare words. However, in contrast with the findings of Watkins et al. (but in agreement with the findings of Experiment 1), incidental learning conditions eliminated the advantage for rare words but did not reverse it. The elimination (rather than the reversal) of the rare-word advantage in recall has therefore been observed in two experiments, using different sets of words and different orienting tasks.

\section{Table 4}

Mean Proportions of Hits and False Alarms as a Function of Group, Word Frequency, and Response Type, Plus $\boldsymbol{A}^{\prime}$, in Experiment 3

\begin{tabular}{|c|c|c|c|c|c|c|}
\hline \multirow{2}{*}{$\begin{array}{l}\text { Response } \\
\text { Type }\end{array}$} & \multicolumn{2}{|c|}{ Hits } & \multicolumn{2}{|c|}{ False Alarms } & \multicolumn{2}{|c|}{$A^{\prime}$} \\
\hline & Common & Rare & Common & Rare & Common & Rare \\
\hline \multicolumn{7}{|c|}{ Intentional } \\
\hline Remember & .32 & .58 & .02 & .00 & & \\
\hline Know & .22 & .15 & .07 & .04 & & \\
\hline Overall & .53 & .71 & .08 & .05 & .82 & .87 \\
\hline \multicolumn{7}{|c|}{ Incidental } \\
\hline Remember & .37 & .62 & .02 & .02 & & \\
\hline Know & .27 & .15 & .04 & .06 & & \\
\hline Overall & .63 & .75 & .06 & .08 & .90 & .90 \\
\hline
\end{tabular}


In contrast with the effects observed in recall, the WFE in recognition memory was reliably observed under both intentional and incidental learning conditions. This finding is consistent with those of Experiment 2 and supports the view that the WFE in recognition memory is independent of intention to learn. An unexpected finding in the false alarm data was that the incidental learning group did not show a mirror effect (e.g., Glanzer \& Adams, 1985, 1990), in contrast with the presence of a mirror effect in both intentional and incidental learning groups in Experiment 2; this result may have been due to the relatively shallow orienting task used in Experiment 3. The absence of a mirror effect is considered further in the General Discussion section.

\section{EXPERIMENT 4}

The findings from Experiments 2 and 3 indicate that the WFE in recognition memory is not the result of a compensatory study strategy that favors the rare words. Both experiments showed that the advantage for rare words was maintained under incidental learning conditions. An alternative explanation of the WFE in recognition memory is that rare words attract more attention than common words when presented in mixed lists, and thus initiate more distinctive encoding (Glanzer \& Adams, 1985, 1990; Glanzer, Adams, Iverson, \& Kim, 1993; Malmberg \& Nelson, 2003). The finding that the WFE is observed in $R$ responses is also consistent with the distinctiveness account of $R$ responses proposed by Rajaram (1996). However, this account does not specify whether distinctiveness is conceptualized in relative or in absolute terms. If the WFE in $R$ responses is due to differences in relative distinctiveness, then the effect should be observed only when participants study mixed lists. Differences in distinctiveness should not be apparent when participants study pure lists featuring only one level of frequency. In support of this view, Dewhurst and Parry (2000) showed that other distinctive items (emotional words) were associated with more $R$ responses than less distinctive items (emotionally neutral words), but only when studied in mixed lists.

Experiment 4 was therefore conducted to test the possibility that the WFE in recognition memory is due to the relative distinctiveness of rare words. Participants studied two pure lists, one of rare words and one of common words, and recognition performance for the two lists was compared. Some previous studies have found a recognition advantage for rare words when presented in pure lists (e.g., Clark \& Burchett, 1994; Gorman, 1961; McCormack \& Swenson, 1972). Experiment 3 was conducted in order to confirm this finding and, in addition, to investigate whether the use of pure lists leads to differences in the subjective experience of recognition for common and rare words. The use of pure lists also provided another test of the compensatory strategy account: Presenting rare and common words in separate lists rendered any differences in the perceived memorability of the words less apparent to participants, who therefore were less likely to adopt a study strategy that favored a subset of words.

\section{Method}

The method was the same as the intentional-read condition of Experiment 2, with the following modifications: A different group of 24 undergraduates took part in two successive recognition experiments, one using rare words and the other using common words. Each study list consisted of 40 words (either all rare or all common). The recognition tests consisted of the 40 studied items plus 40 lures of the same frequency range. The order in which the conditions were presented was counterbalanced so that 12 participants took part in the rare-word condition first and 12 took part in the common-word condition first. Four study lists were constructed, two of rare words and two of common words. Each list provided the targets for half of the participants and lures for the remaining participants. A 5-min filled interval separated the presentation of the two conditions.

\section{Results and Discussion}

The data were entered into a 2 (frequency) $\times 2$ (response type) ANOVA. Table 5 shows the mean proportions of correct and false-positive $R$ and $K$ responses to rare and common words, plus overall hit and false alarm rates and $A^{\prime}$. A significant main effect of frequency was observed in correct recognition, with participants recognizing more rare than common words $[F(1,23)=6.72$, $\left.M S_{\mathrm{e}}=73.50\right]$. The main effect of response type was also significant $\left[F(1,23)=69.98, M S_{\mathrm{e}}=5521.50\right]$, with participants making more $R$ than $K$ responses overall. The interaction between frequency and response type was not significant $\left[F(1,23)=2.32, M S_{\mathrm{e}}=92.04, p=.14\right]$. False alarms were more likely to be categorized as $K$ than as $R$ responses $\left[F(1,23)=27.18, M S_{\mathrm{e}}=345.04\right]$ but were not significantly influenced by frequency $(F<1)$. The $A^{\prime}$ scores were analyzed in a related $t$ test, which showed a reliable effect of frequency $[t(23)=2.37]$, with rare words showing greater discriminability than common words.

The results of Experiment 4 showed that the rare-word advantage in recognition memory was maintained when rare and common words were studied and tested in pure lists. This finding cannot be accounted for by a compensatory study strategy that favors the rare words. This is not to say that rare and common words do not engage different encoding processes or levels of effort. However, such differences in processing appear not to be initiated intentionally by participants. The findings of Experiment 4 also indicate that the rare-word advantage is not

Table 5

Mean Proportions of Hits and False Alarms as a Function of Word Frequency and Response Type, Plus $A^{\prime}$, in Experiment 4 (Pure Lists)

\begin{tabular}{|c|c|c|c|c|c|c|}
\hline \multirow{2}{*}{$\begin{array}{c}\text { Response } \\
\text { Type }\end{array}$} & \multicolumn{2}{|c|}{ Hits } & \multicolumn{2}{|c|}{ False Alarms } & \multicolumn{2}{|c|}{$A^{\prime}$} \\
\hline & Common & Rare & Common & Rare & Common & Rare \\
\hline Remember & .48 & .57 & .02 & .02 & & \\
\hline Know & .16 & .16 & .12 & .11 & & \\
\hline Overall & .64 & .73 & .14 & .13 & .82 & .86 \\
\hline
\end{tabular}


simply the result of rare words' greater distinctiveness relative to common words in the same study list. The null effect of frequency in false alarms contrasts with numerous previous findings of a word frequency mirror effect (e.g., Glanzer \& Adams, 1985, 1990). However, this finding is consistent with the view that the higher false alarm rate usually observed with common words reflects their greater preexperimental familiarity relative to rare words, in which case the effect is less likely to occur with pure lists.

\section{GENERAL DISCUSSION}

Watkins et al. (2000) demonstrated that the mixed-list paradox in recall (superior recall of rare words relative to common words when studied in mixed lists) is eliminated when the words are studied under incidental learning conditions. They argued that participants who study mixed lists containing both rare and common words adopt a compensatory strategy favoring the rare words, thereby overriding the advantage for common words that is typically observed with pure lists. Watkins et al. also argued that incidental learning removed participants' incentive for remembering the words, thereby obviating the compensatory study strategy and restoring the recall advantage for common words. Experiments 1 and 3 of the present study provided some support for this view by showing that an advantage for rare words was obtained under intentional learning conditions but eliminated under incidental learning conditions. The main aim of the present study was to test the possibility that the mixed-list advantage for rare words that is typically observed in recognition memory is also the result of a compensatory study strategy favoring the rare words. In Experiment 2, participants studied mixed lists of rare and common words under either intentional or incidental learning conditions. Experiment 3 eliminated a possible confound in Experiments 1 and 2 by manipulating intention to learn without the use of a pleasantness rating task at encoding. In Experiment 4, rare and common words were studied and tested in pure lists. Despite the different encoding contexts across Experiments 2-4, a recognition advantage for rare over common words was reliably observed in all conditions.

The overall picture emerging from the present study is that the advantage for rare words in recognition memory, unlike that for rare words in recall, is not the result of a compensatory study strategy. There are a number of reasons why a compensatory study strategy might influence recall but not recognition. For example, perhaps a compensatory study strategy is effective only with the short study lists used in tests of recall and becomes ineffective with the long lists typically used in recognition tests. This idea is supported by the finding of Balota and Neely (1980) that the recall advantage for rare words was reversed when participants studied very long (100-item) mixed lists. The dissociation between recall and recognition is also consistent with generate-recognize models of recall (e.g., Anderson \& Bower, 1972). In tests of recognition memory, participants only have to decide if test items were presented at study, whereas in recall, participants have to generate candidate words for themselves. The findings of Watkins et al. (2000) and Experiments 1 and 3 of the present study suggest that a compensatory study strategy increases the availability of rare words at the generation stage. It is possible that incidental learning conditions disrupt the generation stage (thereby eliminating the rare-word advantage in recall with mixed lists) but not the recognition stage (thereby preserving the rare-word advantage in recognition memory).

The present findings suggest the WFE in recognition memory is due to the more distinctive encoding of the rare words, irrespective of participants' intention to remember them. This view is supported by the finding that the WFE is located in the recollection component of recognition memory, as measured by $R$ responses. Although explanations in terms of distinctiveness risk being circular, there are several possible mechanisms by which rare words might be encoded more distinctively than common words. For example, Glanzer and Bowles (1976) suggested that the rare-word advantage is due to rare words' greater overlap of meaning between study and test presentations relative to common words (see also McClelland \& Chappell, 1998). Distinctiveness in this case is defined in terms of the greater consistency of the activated meanings of rare words relative to common words, whose activated meanings vary across presentations. The distinctiveness of rare words has also been attributed to the greater discriminability of their study presentations. For example, Reder, Nhouyvanisvong, Schunn, Ayers, Angstadt, and Hiraki (2000) suggested that rare words are more easily recognized because their study presentations relative to common words have less competition from previous presentations. Participants therefore find it easier to recollect that an item appeared in the current experimental context rather than in some previous context.

Another distinctiveness explanation of the WFE in recognition memory is the proposal by Glanzer and Adams (1985, 1990; Glanzer et al., 1993) that rare words are composed of more distinctive features than common words and therefore attract more attention at encoding. This account was supported by Malmberg, Steyvers, Stephens, and Shiffrin (2002), who found that words consisting of less common letters were better recognized than words consisting of more common letters. Malmberg et al. discussed their findings in relation to the retrieving effectively from memory (REM) model (Shiffrin \& Steyvers, 1997, 1998). According to REM, the features of rare words are less common, and therefore more diagnostic of a prior presentation, than the features of common words. The finding from the present study that the WFE in recognition memory is independent of intention to learn suggests participants are sensitive to the distinctiveness of word features whenever they read a word, and not simply when preparing for a memory test. However, Malmberg et al. also found an effect of word 
frequency when letter frequency was controlled, and they concluded that the frequency of individual features is only one of the factors that can lead to a WFE.

The finding from Experiment 4 of a WFE in recognition memory with pure lists suggests that the WFE is not simply an effect of relative distinctiveness. This result is in contrast to the finding of Dewhurst and Parry (2000) that the effect of word emotionality in recognition memory (more $R$ responses to emotional than to neutral words) was eliminated in a pure-list design, and it suggests that rare words initiate distinctive encoding over and above the effects of relative distinctiveness. The presence of a WFE with pure lists is also consistent with the conclusion of Malmberg and Nelson (2003) that rare words do not borrow encoding resources from common words. They argued that frequency influences the resources allocated to the initial identification of a word rather than those allocated to encoding words into long-term memory (see Mutter \& Hashtroudi, 1987, who also concluded that rare words involve more effortful identification processes). As noted by Malmberg and Nelson, the finding that rare words inherently require more attentional resources in order to be identified is consistent with the presence of a WFE in both mixed and pure lists.

One unexpected finding of the present study was the elimination of the mirror effect in recognition memory by incidental learning with a shallow encoding task (Experiment 3) and by the use of pure lists (Experiment 4). These findings are inconsistent with accounts of the WFE that attribute the effects in hits and false alarms to a single underlying factor (e.g., Glanzer et al., 1993; Shiffrin \& Steyvers, 1997), as such models predict that an increase in hits to rare words should be accompanied by a decrease in false alarms. The present findings are more supportive of dual-process accounts of the WFE, which propose that the effects of frequency in hits and false alarms are independent (e.g., Joordens \& Hockley, 2000; Reder et al., 2000). As discussed above, the rare-word advantage in hits has been attributed to the tendency for rare words to attract more attention at encoding than common words (Glanzer \& Adams, 1985, 1990; Glanzer et al., 1993; Malmberg et al., 2002) or to the fact that rare words have less contextual competition than common words (Reder et al., 2000). In dual-process models, the reversed effect of frequency in false alarms has been attributed to the nonstudied rare words having distinctive properties that make them more easily discriminable from studied items stored in memory (e.g., Earhard, 1982) or to the more extensive exposure history of common words (Reder et al., 2000). Irrespective of the processes that underlie the WFE in hits and false alarms, the elimination of the mirror effect in the present study is consistent with the view that the effects of word frequency in hits and false alarms are independent (see Hirshman \& Arndt, 1997, and Arndt \& Reder, 2002, for further evidence in support of dual-process accounts of the WFE).

To summarize, the present results add to the many previous findings that the effects of word frequency depend on whether memory is tested for recall or for recognition. The main finding from the present study is that incidental learning eliminated the rare-word advantage in recall but not in recognition memory. The findings from Experiments 1 and 3 support the suggestion of Watkins et al. (2000) that the recall advantage for rare words in mixed lists is the result of a compensatory study strategy favoring the rare words. In contrast, the findings from Experiments 2, 3, and 4 indicate that the rare-word advantage in recognition memory is not the result of such a strategy. The recognition advantage for rare words was independent of intention to learn and was reliably observed with both mixed and pure lists. The presence of the WFE in $R$ responses also confirms previous findings that word frequency influences the recollection component of recognition memory (Dewhurst et al., 1998; Gardiner \& Java, 1990; Kinoshita, 1995). Overall, the present findings suggest the WFE in recognition memory occurs because rare words are encoded more distinctively than common words, irrespective both of participants' intention to remember them and of the context in which they are studied (i.e., mixed or pure lists).

\section{REFERENCES}

Allen, L. R., \& Garton, R. F. (1968). The influence of word-knowledge on the word-frequency effect in recognition memory. Psychonomic Science, 10, 401-402.

Anderson, J. R., \& Bower, G. H. (1972). Recognition and retrieval processes in free recall. Psychological Review, 79, 97-123.

ARNDT, J., \& REDER, L. M. (2002). Word frequency and receiver operating characteristic curves in recognition memory: Evidence for a dual-process interpretation. Journal of Experimental Psychology: Learning, Memory, \& Cognition, 28, 830-842.

BAAYen, R. H., PiePenbrock, R., \& Gulikers, L. (1995). CELEX lexical database [CD-ROM]. Philadelphia: University of Pennsylvania, Linguistic Data Consortium.

Balota, D. A., \& NeEly, J. H. (1980). Test-expectancy and wordfrequency effects in recall and recognition. Journal of Experimental Psychology: Human Learning \& Memory, 6, 576-687.

Clark, S. E., \& Burchett, R. E. R. (1994). Word frequency and list composition effects in associative recognition and recall. Memory \& Cognition, 22, 55-62.

DeLosh, E. L., \& McDAniel, M. A. (1996). The role of order information in free recall: Application to the word-frequency effect. Journal of Experimental Psychology: Learning, Memory, \& Cognition, 22, 1136-1146.

DEWHURST, S. A., \& Hitch, G. J. (1999). Cognitive effort and recollective experience in recognition memory. Memory, 7, 129-146.

Dewhurst, S. A., Hitch, G. J., \& BARry, C. (1998). Separate effects of word frequency and age of acquisition in recognition and recall. Journal of Experimental Psychology: Learning, Memory, \& Cognition, 24, 284-298.

DeWhurst, S. A., \& PArry, L. A. (2000). Emotionality, distinctiveness, and recollective experience. European Journal of Cognitive Psychology, 12, 541-551.

DuCHEK, J. M., \& NeEly, J. H. (1989). A dissociative wordfrequency $\times$ levels-of-processing interaction in episodic recognition and lexical decision tasks. Memory \& Cognition, 17, 148-162.

EARHARD, B. (1982). Determinants of the word-frequency effect in recognition memory. Memory \& Cognition, 10, 115-124.

Gardiner, J. M. (1988). Functional aspects of recollective experience. Memory \& Cognition, 16, 309-313.

GARDINER, J. M., \& JAVA, R. I. (1990). Recollective experience in word and nonword recognition. Memory \& Cognition, 18, 23-30. 
Gerhand, S., \& BARry, C. (1999). Age of acquisition, word frequency, and the role of phonology in the lexical decision task. Memory \& Cognition, 27, 592-602.

GILHOOLY, K. J., \& LOGIE, R. H. (1980). Age-of-acquisition, imagery, concreteness, familiarity, and ambiguity measures for 1,944 words. Behavior Research Methods \& Instrumentation, 12, 395-427.

Gillund, G., \& Shiffrin, R. M. (1984). A retrieval model for both recognition and recall. Psychological Review, 91, 1-67.

GlanZER, M., \& ADAMS, J. K. (1985). The mirror effect in recognition memory. Memory \& Cognition, 13, 8-20.

GlanZer, M., \& ADAMS, J. K. (1990). The mirror effect in recognition memory: Data and theory. Journal of Experimental Psychology: Learning, Memory, \& Cognition, 16, 5-16.

Glanzer, M., Adams, J. K., Iverson, G. J., \& Kim, K. (1993). The regularities of recognition memory. Psychological Review, 100, 546-567.

GlanZer, M., \& Bowles, N. (1976). Analysis of the word-frequency effect in recognition memory. Journal of Experimental Psychology: Human Learning \& Memory, 2, 21-31.

GoRMAN, A. M. (1961). Recognition memory for nouns as a function of abstractness and frequency. Journal of Experimental Psychology, $\mathbf{6 1}_{2}$ 23-29.

GREENE, R. L., \& ThapaR, A. (1994). Mirror effect in frequency discrimination. Journal of Experimental Psychology: Learning, Memory, \& Cognition, 20, 946-952.

GREGG, V. H. (1976). Word frequency, recognition, and recall. In J. Brown (Ed.), Recall and recognition (pp. 183-216). New York: Wiley.

Gregg, V. H., Montgomery, D., \& Castano, D. (1980). Recall of common and uncommon words from single and mixed lists. Journal of Verbal Learning \& Verbal Behavior, 19, 240-245.

Hirshman, E., \& ARndT, J. (1997). Discriminating alternative conceptions of false recognition: The cases of word concreteness and word frequency. Journal of Experimental Psychology: Learning, Memory, \& Cognition, 23, 1306-1323.

Hirshman, E., \& PALIJ, M. (1992). Rehearsal and the word frequency effect in recognition memory. Journal of Memory \& Language, $\mathbf{3 1}$, 477-484.

JACOBY, L. L., \& DALlas, M. (1981). On the relationship between autobiographical memory and perceptual learning. Journal of Experimental Psychology: General, 3, 306-340.

Joordens, S., \& HockLey, W. E. (2000). Recollection and familiarity through the looking glass: When old does not mirror new. Journal of Experimental Psychology: Learning, Memory, \& Cognition, 26, 1534-1555.

Kim, K., \& Glanzer, M. (1993). Speed versus accuracy instructions, study time, and the mirror effect. Journal of Experimental Psychology: Learning, Memory, \& Cognition, 19, 638-652.

KinOSHITA, S. (1995). The word frequency effect in recognition memory versus repetition priming. Memory \& Cognition, 23, 569-580.

KuČERA, H., \& FrANCIS, W. (1967). Computational analysis of presentday American English. Providence, RI: Brown University Press.

MacLeOD, C. M., \& KAMPE, K. E. (1996). Word frequency effects in recall, recognition, and word fragment completion tests. Journal of Experimental Psychology: Learning, Memory, \& Cognition, 22, 132-142.
Malmberg, K. J., \& Nelson, T. O. (2003). The word frequency effect for recognition memory and the elevated-attention hypothesis. Memory \& Cognition, 31, 35-43.

Malmberg, K. J., STEYvers, M., Stephens, J. D., \& Shiffrin, R. M. (2002). Feature frequency effects in recognition memory. Memory \& Cognition, 30, 607-613.

MANDLER, G. (1980). Recognizing: The judgment of previous occurrence. Psychological Review, 87, 252-271.

MAY, R. B., \& TRYK, H. E. (1970). Word sequence, word frequency, and free recall. Canadian Journal of Psychology, 24, 299-304.

McClelland, J. L., \& Chappell, M. (1998). Familiarity breeds differentiation: A subjective-likelihood approach to the effects of experience in recognition memory. Psychological Review, 105, 724760.

McCoRmack, P. D. (1972). Recognition memory: How complex a retrieval system? Canadian Journal of Psychology, 26, 19-41.

McCormack, P. D., \& Swenson, A. L. (1972). Recognition memory for common and rare words. Journal of Experimental Psychology, 95, 72-77.

MUTter, S. A., \& Hashtroudi, S. (1987). Cognitive effort and the word frequency effect on recognition and lexical decision. American Journal of Psychology, 100, 93-116.

RAJARAM, S. (1996). Perceptual effects on remembering: Recollective processes in picture recognition memory. Journal of Experimental Psychology: Learning, Memory, \& Cognition, 22, 365-377.

RAO, K. V., \& PROCTOR, R. W. (1984). Study-phase processing and the word frequency effect in recognition memory. Journal of Experimental Psychology: Learning, Memory, \& Cognition, 10, 386-394.

ReDer, L. M., Nhouyvanisvong, A., Schunn, C. D., AYers, M. S., Angstadt, P., \& HiraKi, K. (2000). A mechanistic account of the mirror effect for word frequency: A computational model of rememberknow judgments in a continuous recognition paradigm. Journal of Experimental Psychology: Learning, Memory, \& Cognition, 26, 294-320.

SHEPARD, R. N. (1967). Recognition memory for words, sentences, and pictures. Journal of Verbal Learning \& Verbal Behavior, 6, 156-163.

ShIFFrIN, R. M., \& STEYVERS, M. (1997). A model for recognition memory: REM - Retrieving effectively from memory. Psychonomic Bulletin \& Review, 4, 145-166.

SHIFFrIN, R. M., \& STEYVERS, M. (1998). The effectiveness of retrieval from memory. In M. Oaksford \& N. Chater (Eds.), Rational models of cognition (pp. 73-95). Oxford: Oxford University Press.

Tulving, E. (1985). Memory and consciousness. Canadian Psychologist, 26, 1-12.

WatKins, M. J., LeCompte, D. C., \& KIM, K. (2000). Role of study strategy in recall of mixed lists of common and rare words. Journal of Experimental Psychology: Learning, Memory, \& Cognition, 26, 239-245.

WiXTED, J. T. (1992). Subjective memorability and the mirror effect. Journal of Experimental Psychology: Learning, Memory, \& Cognition, 18, 681-690.

(Manuscript received March 19, 2003; revision accepted for publication April 21, 2004.) 